\title{
Beroul, Tristano e Isotta
}

\section{Giuseppe Noto}

\section{(2) OpenEdition}

\section{Journals}

\section{Edizione digitale}

URL: http://journals.openedition.org/studifrancesi/328

DOI: 10.4000/studifrancesi.328

ISSN: 2427-5856

\section{Editore}

Rosenberg \& Sellier

\section{Edizione cartacea}

Data di pubblicazione: 1 aprile 2015

Paginazione: 122

ISSN: 0039-2944

\section{Notizia bibliografica digitale}

Giuseppe Noto, «Beroul, Tristano e Isotta », Studi Francesi [Online], 175 (LIX |I) | 2015, online dal 01 avril 2015, consultato il 18 septembre 2020. URL : http://journals.openedition.org/studifrancesi/328 ; DOI : https://doi.org/10.4000/studifrancesi.328

Questo documento è stato generato automaticamente il 18 settembre 2020.

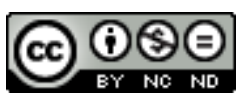

Studi Francesi è distribuita con Licenza Creative Commons Attribuzione - Non commerciale - Non opere derivate 4.0 Internazionale. 


\title{
Beroul, Tristano e Isotta
}

\author{
Giuseppe Noto
}

\section{NOTIZIA}

BEROUL, Tristano e Isotta, a cura di Gioia Paradisi, Alessandria, Edizioni dell'Orso, 2013

(«Gli Orsatti. Testi per un Altro Medioevo», 35), pp. 419.

1 Il Tristan di Béroul (autore che lavora in Inghilterra e scrive in normanno) è tràdito da un unico testimone (il parigino BnF fr. 2171), il quale ci consegna 4495 versi (mancano la parte iniziale e quella finale). L'opera è da collocarsi, a parere della maggior parte degli studiosi, tra gli anni Sessanta ed i primi Ottanta del xII secolo, pur se nessuno degli elementi valutabili ai fini di una datazione è tale da essere realmente dirimente.

Il volume curato da Gioia PARADISI offre finalmente - e se ne sentiva davvero la mancanza - una traduzione in italiano, accompagnata da una densa introduzione e da note filologiche ed esegetiche, dell'opera, fondandosi su un testo critico affidabile costituito sulla base del testimone unico e in un'ottica «conservativa» (e comunque sempre segnalando tramite asterisco ogni intervento), pur se la curatrice interviene laddove a suo avviso necessario e tenendo conto (ottimamente) delle principali edizioni preesistenti e dei contributi specialistici di taglio ecdotico. L'apparato affianca ai dati relativi alle lezioni rigettate la discussione di una serie di loci significativi sia dal punto di vista della constitutio textus sia sotto il rilievo filologico ed interpretativo.

3 Nell'«Introduzione» si segnalano in particolare per interesse e originalità le osservazioni sugli aspetti essenziali che l'amore incarnato da Tristano e Isotta riveste nella versione elaborata da Béroul: un amore ben lontano dall'avere come "paradigma di riferimento» il «codice comportamentale tipico degli innamorati proposto dalla lirica d'amore» (p. 16). Notevole anche l'analisi del percorso che ha portato una storia legata nei suoi nuclei più antichi alla trasmissione del potere regale a divenire una vicenda d'amore, così come l'approfondimento delle relazioni che la vicenda instaura con i racconti della tradizione celtica. 
4 Forse, pensando alla «spendibilità» didattica del volume, sarebbe stata necessaria qualche nota esegetica in più, così come sarebbe stato auspicabile accompagnare con una traduzione i testi letterari in antico francese diversi dal Tristan citati. Va tuttavia notato che è la curatrice stessa a dichiarare che «in attesa di una più ampia pubblicazione, nella quale possano figurare lo studio analitico della veste graficolinguistica e della versificazione, il glossario e un commento più completo, si presentano in questa sede il testo critico, la traduzione e una strumentazione esegetica essenziale» (p. 47, nota).

5 Chiude il volume una ricca e ben organizzata «Bibliografia». 